\title{
Perspective
}

\section{What the Amygdala Does and Doesn't Do in Aversive Learning}

\author{
Stephen Maren
}

Department of Psychology, University of Michigan, Ann Arbor, Michigan 48109-1109, USA

Whether you are a rat or a rabbit or a mouse or a monkey, your brain is constantly learning. Indeed, one could argue that this is one of the primary purposes of the nervous system: to adapt behavior to changing environments by storing a record of experience. When experiences are aversive, the type of learning that encodes memories of such events is generally called 'aversive learning.' And although aversive learning is normally adaptive, it occasionally goes awry and contributes to the pathology associated with clinical disorders of fear and anxiety, such as posttraumatic stress disorder. As such, there is an urgent need to understand the behavioral principles and brain mechanisms of aversive learning.

In recent years, an impressive body of literature has implicated the amygdala, a collection of nuclei buried deep within the temporal lobe, in aversive learning (McGaugh 1989; Davis 1992; LeDoux 2000; Calder et al. 2001; Davis and Whalen 2001; Maren 2001). Notably, the amygdala is critical for Pavlovian fear conditioning, a form of classical conditioning in which animals learn relationships between aversive events and the stimuli that predict them. In particular, numerous studies indicate that either neurotoxic lesions or pharmacological inactivation of the basolateral amygdaloid complex (BLA; comprised of the lateral, basolateral, and basomedial amygdaloid nuclei) disrupts the acquisition and expression of Pavlovian fear memories (Helmstetter and Bellgowan 1994; Campeau and Davis 1995; Maren et al. 1996; Muller et al. 1997; Cousens and Otto 1998). There is only one instance in which rats with BLA lesions exhibit conditional fear responses, and that occurs following extensive overtraining (Maren 1998, 1999).

However, a recent report challenges the view that the amygdala is required for learning Pavlovian associations during aversive conditioning. In a recent issue of Learning \& Memory, Lehmann et al. (2003) report experiments suggesting that the amygdala is not essential for the learning that occurs when rats are exposed to an electrified shock probe, a procedure they call "shock-probe fear conditioning." In two experiments those authors infused tetrodotoxin (TTX), which reversibly inhibits neuronal activity, into the BLA prior to shock-probe fear conditioning. They found that TTX infusions into the BLA affected probe avoidance during training, with BLA-treated rats contacting the probe more than five times as often as controls. However, Lehmann and colleagues found that retention of the shock-probe training, which was indexed by measuring the number of contacts the rats made with the probe four days after training, was minimally affected by BLA inactivation. The authors concluded that "... the amygdala is not necessary for the acquisition of the association between the shock and the cue, but is involved in some other process that influences performance" (Lehmann et al. 2003). On the face of it, this conclusion challenges a widely held view that the BLA is importantly involved, if not essential under

E-MAIL maren@umich.edu; FAX (734) 763-7480.

Article and publication are at http://www.learnmem.org/cgi/doi/10.1101/ Im.68403. most circumstances, for the acquisition of stimulus-stimulus associations that underlie long-term memories for Pavlovian fear conditioning.

But is the essence of learning and memory in the shockprobe task a Pavlovian association? Lehmann et al. imply that avoidance performance in the shock-probe task is guided by "the association between the shock and the cue" and have labeled this learning "shock-probe fear conditioning." Because our ability to assign function to brain systems in learning tasks is only as good as our understanding of the psychological processes underlying those tasks, it is essential that we understand the learning mechanisms that govern "shock-probe fear conditioning" before concluding that the amygdala is or isn't involved.

To understand aversive learning, experimental psychologists and behavioral neuroscientists have developed laboratory paradigms that attempt to distill fundamental psychological processes under experimentally controlled conditions. For example, repeated presentation of an aversive stimulus, such as a loud noise, is used to study nonassociative learning processes including habituation and sensitization. Contingent and response-independent presentations of two different stimuli, such as an innocuous tone and an aversive footshock, is used to study Pavlovian (classical) conditioning. Contingent but response-dependent presentation of a stimulus, such as delivering footshock to an animal when it crosses into a dark compartment, is used to study instrumental (operant) conditioning. One primary goal of neuroscience is to understand the neural mechanisms of these types of learning. And although they may appear simple, at least in a procedural sense, there is more complexity than meets the eye. Aversive learning is not monolithic in either a psychological or neurobiological sense. Many sensory, motivational, and motor processes serve it, and it requires the coordinated operation of many neural systems. The involvement of multiple psychological processes and neural systems in aversive learning is a testament to its complexity and importance.

When rats are submitted to "shock-probe fear conditioning," they are placed in an enclosure containing a wire-wrapped and electrified probe extending from one wall (Fig. 1). During exploration of the enclosure, rats invariably approach the probe and receive a brief electric shock, typically to the nose. After receiving one or more shocks, rats come to avoid the probe and will make many fewer contacts with the electrified probe during later retention tests. In addition, rats will spray bedding or other substrates (if available) at the probe to bury it. Probe burying is thought to be a species-specific defense response emitted to focal aversive stimuli (Pinel and Treit 1978; but see Fanselow et al. 1987). Importantly, both probe avoidance and burying reduce the number of shocks an animal receives, and thereby would be expected to be under the control of instrumental contingencies. Therefore, "shock-probe fear conditioning" involves not only a Pavlovian contingency, but also an instrumental contingency. Pavlovian conditioning of probe-shock and context-shock associations yields conditioned fear responses (such as freezing) to the probe or enclosure, whereas instrumental conditioning of 

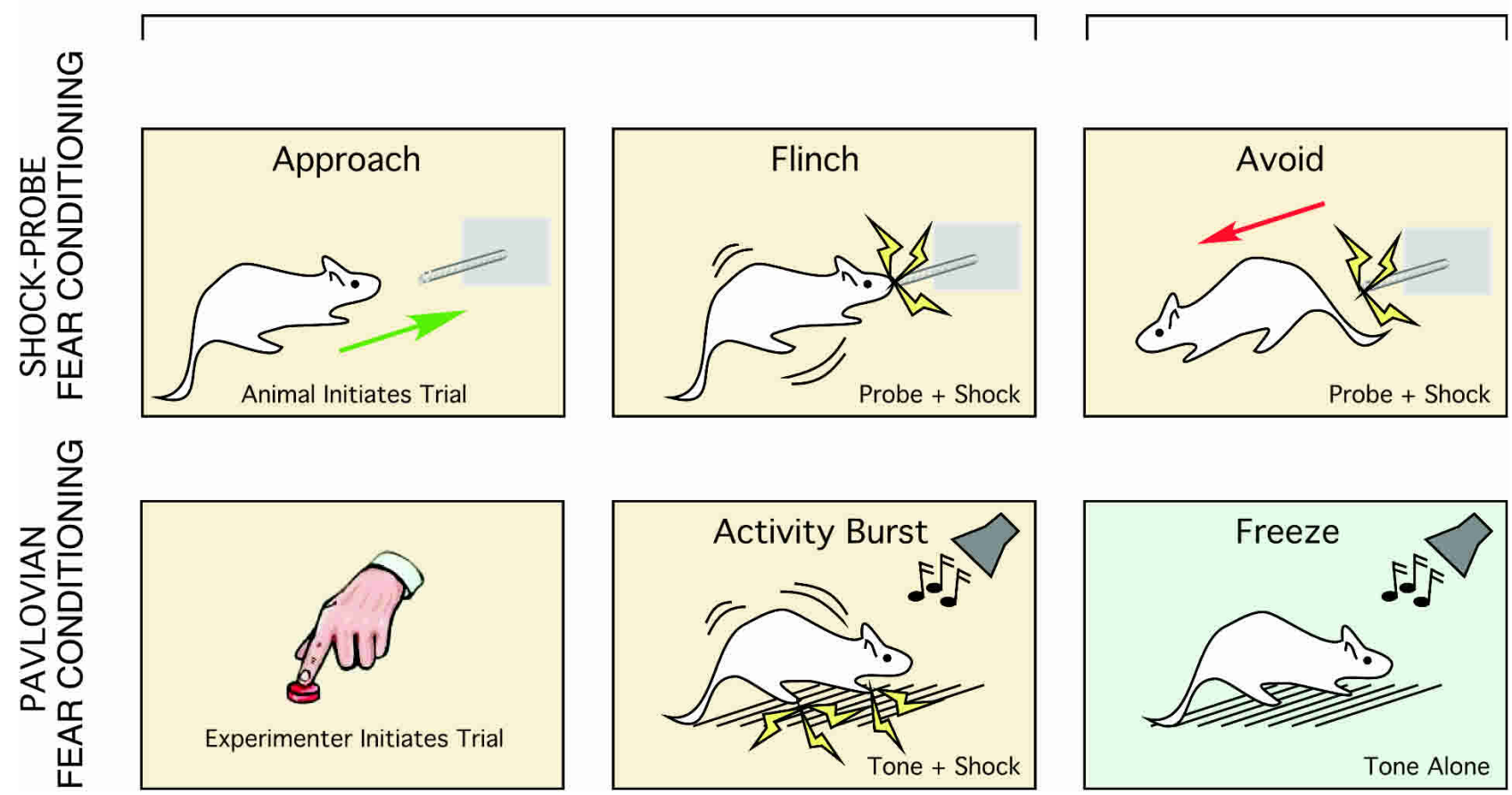

Figure 1 Experimental procedures and behavior in shock-probe and Pavlovian fear conditioning in rats. In shock-probe fear conditioning, rats voluntarily approach an electrified shock-probe. Contact with the electrified probe is aversive and yields both Pavlovian and instrumental associations that support avoidance behavior during later retention testing. Probe contact and shock delivery are contingent upon the animal's behavior. During Pavlovian fear conditioning, in contrast, an experimenter initiates conditioning trials in which a discrete or contextual conditional stimulus (CS) is followed by an aversive footshock unconditional stimulus (US). CS and US delivery are not contingent on the animal's behavior. Pavlovian associations between CS and US yield conditional fear responses, such as freezing, that are expressed to the CS during later retention testing in a novel context.

probe-approach and approach-shock associations promotes instrumental avoidance of the probe. Nonassociative sensitization of fear may also play a role in regulating behavior during shockprobe training. As such, the term "shock-probe fear conditioning" is misleading because it implies that the process and procedure are fundamentally Pavlovian. Indeed, the shock-probe procedure contrasts significantly with that in a typical Pavlovian fear conditioning session in which a tone is paired with footshock, for example. In a true Pavlovian fear conditioning procedure, the animal does not control stimulus delivery; the onset of tones and footshocks, for example, are scheduled and administered by the experimenter. Indeed, the shock-probe procedure is more aptly named "shock-probe avoidance conditioning" to reflect the instrumental contingency in the task.

The response requirement in the shock-probe test has important implications for the underlying neural substrates. Indeed, there is considerable evidence to suggest that instrumental contingencies, whether for conditional stimulus (CS) or unconditional stimulus (US) delivery, weaken the involvement of the amygdala in aversive learning tasks. In the conditioned taste aversion (CTA) paradigm, for example, Schafe et al. (1998) demonstrated that the conditioning procedure determines whether the learning is sensitive to neurotoxic amygdala lesions. If animals are required to make an instrumental response for the saccharin CS (a standard procedure in which the animal approaches a sipper tube containing saccharin), then the CTA is not affected by neurotoxic amygdala lesions. However, if the saccharin CS is infused directly across the tongue, a Pavlovian procedure for which there is no response requirement, then the CTA is sensitive to amygdala lesions. This pattern of results has also emerged in shock-motivated conditioning tasks. Lesions of the BLA, which normally disrupt Pavlovian fear conditioning, have weak effects when animals are required to press a lever to initiate trial delivery (CS and US onset; Killcross et al. 1997). Furthermore, there is ample evidence suggesting that inhibitory avoidance procedures, which require animals to make a response to receive footshock, are often immune to BLA lesions (McNew and Thompson 1966; Tomaz et al. 1992; Roozendaal and McGaugh 1997). Hence aversive conditioning procedures that require an instrumental response are less dependent on the BLA, whereas those that do not (i.e., true Pavlovian procedures) require the BLA.

Because "shock-probe fear conditioning" involves both Pavlovian and instrumental associations, it is not surprising that BLA inactivation is not sufficient to disrupt the retention of probe avoidance. Animals receiving intra-amygdaloid TTX infusions in the Lehmann et al. (2003) study may have ultimately learned to avoid the shock probe using instrumental associations not requiring the amygdala. Indeed, as two-process models of avoidance learning might suggest, BLA inactivation had a potent effect early in training, when Pavlovian conditioning predominates the avoidance learning experience, but not later during retention testing, when instrumental contingencies predominate (Mineka and Gino 1980). If true, an interesting prediction is that the retention performance of rats that acquire probe avoidance under BLA inactivation should be more sensitive than that of intact rats to the imposition of omission contingencies, which are known to strongly affect instrumental performance. Likewise, retention performance in intact rats may be more sensitive to the extinction of Pavlovian fear (e.g., by exposing rats to the conditioning context), than are rats trained under TTX inactivation. It would also be informative to examine whether BLA inactivation has more profound effects on defensive behaviors that are generated by Pavlovian contingencies, including freezing and possi- 
bly probe burying itself (Fanselow et al. 1987). Until these avenues are explored, it is premature to conclude that the amygdala is not required for forming Pavlovian cue-shock associations during shock-probe training. Rather, it seems more reasonable to conclude that the amygdala is required for these Pavlovian associations, but is not required for learning response contingencies that support instrumental avoidance.

\section{ACKNOWLEDGMENTS}

This work was supported by the National Institutes of Health (R01 MH65961).

\section{REFERENCES}

Calder, A.J., Lawrence, A.D., and Young, A.W. 2001. Neuropsychology of fear and loathing. Nat. Rev. Neurosci. 2: 352-363.

Campeau, S. and Davis, M. 1995. Involvement of the central nucleus and basolateral complex of the amygdala in fear conditioning measured with fear-potentiated startle in rats trained concurrently with auditory and visual conditioned stimuli. J. Neurosci. 15: 2301-2311.

Cousens, G. and Otto, T. 1998. Both pre- and posttraining excitotoxic lesions of the basolateral amygdala abolish the expression of olfactory and contextual fear conditioning. Behav. Neurosci. 112: $1092-1103$.

Davis, M. 1992. The role of the amygdala in fear and anxiety. Annu. Rev. Neurosci. 5: 353-375.

Davis, M. and Whalen, P.J. 2001. The amygdala: Vigilance and emotion. Mol. Psych. 6: 13-34.

Fanselow, M.S., Sigmundi, R.A., and Williams, J.L. 1987. Response selection and the hierarchical organization of species-specific defense reactions: The relationship between freezing, flight, and defensive burying. Psychol. Rec. 37: 381-386.

Helmstetter, F.J. and Bellgowan, P.S. 1994. Effects of muscimol applied to the basolateral amygdala on acquisition and expression of contextual fear conditioning in rats. Behav. Neurosci. 108: 1005-1009.

Killcross, S., Robbins, T.W., and Everitt, B.J. 1997. Different types of fear-conditioned behaviour mediated by separate nuclei within amygdala. Nature 388: 377-380.
LeDoux, J.E. 2000. Emotion circuits in the brain. Annu. Rev. Neurosci. 23: $155-184$.

Lehmann, H., Treit, D., and Parent, M.B. 2003. Spared anterograde memory for shock-probe fear conditioning after inactivation of the amygdala. Learn. Mem. 10: 261-269.

Maren, S. 1998. Overtraining does not mitigate contextual fear conditioning deficits produced by neurotoxic lesions of the basolateral amygdala. J. Neurosci. 18: 3088-3097.

- 1999. Neurotoxic basolateral amygdala lesions impair learning and memory but not the performance of conditional fear in rats. $J$. Neurosci. 19: 8696-8703.

. 2001. Neurobiology of Pavlovian fear conditioning. Annu. Rev. Neurosci. 24: 897-931.

Maren, S., Aharonov, G., and Fanselow, M.S. 1996. Retrograde abolition of conditional fear after excitotoxic lesions in the basolateral amygdala of rats: Absence of a temporal gradient. Behav. Neurosci. 110: $718-726$.

McGaugh, J.L. 1989. Involvement of hormonal and neuromodulatory systems in the regulation of memory storage. Annu. Rev. Neurosci. 12: $255-287$.

McNew, J.J. and Thompson, R. 1966. Role of the limbic system in active and passive avoidance conditioning in the rat. J. Comp. Physiol. Psychol. 61: 173-180.

Mineka, S. and Gino, A. 1980. Dissociation between conditioned emotional response and extended avoidance performance. Learn. Motiv. 11: 476-502.

Muller, J., Corodimas, K.P., Fridel, Z., and LeDoux, J.E. 1997. Functional inactivation of the lateral and basal nuclei of the amygdala by muscimol infusion prevents fear conditioning to an explicit conditioned stimulus and to contextual stimuli. Behav. Neurosci. 111: 683-691.

Pinel, J.P. and Treit, D. 1978. Burying as a defensive response in rats. J. Comp. Physiol. Psychol. 92: 708-712.

Roozendaal, B. and McGaugh, J.L. 1997. Basolateral amygdala lesions block the memory-enhancing effect of glucocorticoid administration in the dorsal hippocampus of rats. Eur. J. Neurosci. 9: 76-83.

Schafe, G.E., Thiele, T.E., and Bernstein, I.L. 1998. Conditioning method dramatically alters the role of amygdala in taste aversion learning. Learn. Mem. 5: 481-492.

Tomaz C., Dickinson-Anson, H., and McGaugh, J.L. 1992. Basolateral amygdala lesions block diazepam-induced anterograde amnesia in an inhibitory avoidance task. Proc. Natl. Acad. Sci. 89: 3615-3619. 


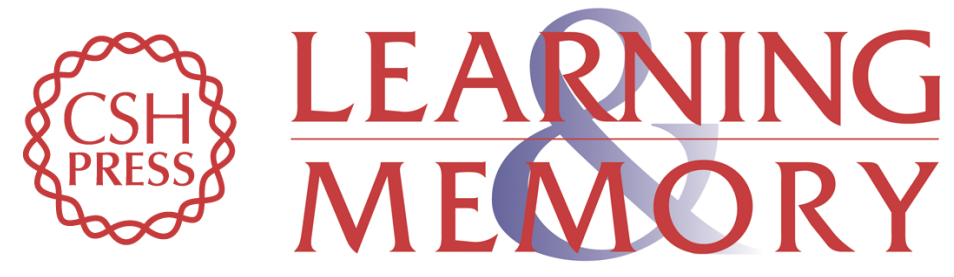

\section{What the Amygdala Does and Doesn't Do in Aversive Learning}

Stephen Maren

Learn. Mem. 2003, 10:

Access the most recent version at doi:10.1101/lm.68403

References This article cites 22 articles, 6 of which can be accessed free at: http://learnmem.cshlp.org/content/10/5/306.full.html\#ref-list-1

License

Email Alerting Receive free email alerts when new articles cite this article - sign up in the box at the Service top right corner of the article or click here. 